\title{
Simultaneous HPLC Determination of Marker Compounds for the Standardization of Hedyotis diffusa
}

\author{
Han-Yeol Bang ${ }^{1}$, Eun-Ju Yang ${ }^{2}$, Jeong-Ah Kim² and Kyung-Sik Song ${ }^{2 *}$ \\ ${ }^{1}$ Department of Agricultural Chemistry, Kyungpook National University, Daegu 702-701, Korea \\ ${ }^{2}$ Research Institute of Pharmaceutical Sciences, College of Pharmacy, Kyungpook National University, Daegu 702-701, Korea
}

Received July 25 10, 2013 / Revised August 2 9, 2013 /Accepted August 2, 2013

\begin{abstract}
From a 95\% ethanolic extract of $H$. diffusa, four marker compounds (HD1 HD4) were isolated, which were relatively unique and exist in comparably high contents. The structures of marker compounds were identified as digitolutein (1), 2-hydroxy-3-methylanthraquinone (2), (E/ Z)-6-O-p-coumaroyl scandoside methyl ester (4:1 mixture) (3), and $(E / Z)$-6- $O$-pmethoxycinnamoyl scandoside methyl ester (4:1 mixture) (4), respectively, on the basis of ${ }^{13} \mathrm{C}$ and ${ }^{1} \mathrm{H}-\mathrm{NMR}$ analyses. The calibration curves of marker compounds showed high linearity, as their correlation coefficient $\left(\mathrm{R}^{2}\right)$ were in the range of 0.9991 0.9999. In addition, the limit of detection (LOD) and the limit of quantification (LOQ) were $0.03 \sim 0.07$ $\mu \mathrm{g} / \mathrm{ml}$ and $0.099 \sim 0.231 \mu \mathrm{g} / \mathrm{ml}$, respectively. The intra-day/inter-day precision and accuracy were $0.23 \sim 2.00 \% / 0.25 \sim 1.16 \%$ and $94.60 \sim 108.44 \% / 94.73-110.23 \%$, respectively. The optimal HPLC conditions for the simultaneous quantification of HD1 HD4 were as follows: stationary phase; Merck Chromolith RP-18e $(100 \times 4.6 \mathrm{~mm}, 5 \mu \mathrm{m})$, column temp.; room temperature, UV detection at $280 \mathrm{~nm}$, flow rate; 2.0 $\mathrm{ml} / \mathrm{min}$, injection volume; $10 \mu \mathrm{l}$, mobile phase; start with the mixture of $80 \%$ solvent $\mathrm{A}\left(\mathrm{H}_{2} \mathrm{O}\right.$ containing $0.5 \%$ acetic acid) and $20 \%$ solvent B (methanol containing $0.5 \%$ acetic acid) and gradually decrease solvent $\mathrm{A}$ to $40 \%$ in $9 \mathrm{~min}$., then retain this condition to $18 \mathrm{~min}$. Under the HPLC condition, the four marker compounds 1 4 were successfully separated without any interference of other constituents. The results obtained in this study are expected to be helpful for the development of nutraceutics and natural medicines and for the quality control of this plant.
\end{abstract}

Key words : Anthraquinone, Hedyotis diffusa, HPLC quantification, iridoid, simultaneous analysis

\section{서 론}

백운풀(Hedyotis diffusa Willd.)은 쌍떡잎식물 꼭두서니목 꼭두서니과의 한해살이 풀이며 백화사설초라고도 한다. 중국, 일본, 대만 등에 분포하고 있으며 국내에서는 제주도 한라산, 전남 백운산 습지 등에 서식하고 있다. 예로부터 민간에서는 유사한 외형을 지닌 중국산 산방화이초(H corymbosa)를 항암 제로 수입하여 사용해왔었다. 그로 인해 우리나라 토종 백운 풀은 멸종위기에 처하게 되었으며, 국내 학계에서 조차 토종 백운풀에 대한 연구는 소외되고 있는 형편이다. 더구나 국내 에서 백운풀로 재배되는 것은 산방화이초로 백운풀과의 명확 한 구분 없이 혼용하여 연구재료로 사용하고 있다. 토종 백운 풀은 엽액에서 짧은 꽃대에 흰 꽃이 1 개 또는 2 개가 대생으로 피는 특징이 있는 반면, 산방화이초는 엽액에서 긴 꽃대에 취

\footnotetext{
*Corresponding author

Tel : +82-53-950-8565, Fax : +82-53-950-8557

E-mail : kssong@knu.ac.kr

This is an Open-Access article distributed under the terms of the Creative Commons Attribution Non-Commercial License (http://creativecommons.org/licenses/by-nc/3.0) which permits unrestricted non-commercial use, distribution, and reproduction in any medium, provided the original work is properly cited
}

산화서로 피는 모양을 볼 수 있다. 잎의 모양도, 백운풀은 더 가늘고 뾰족하나 산방화이초는 상대적으로 두껍고 둔탁한 편 이다. 또한 백운풀은 마우스 경구 급성독성시험 결과 투여 후 60 일 동안 생존율에 변화를 주지 않았으며, 체중 및 간에 대한 영향으로 간 기능 검사 지표인 aspartate aminotransferase (ALT), alanine aminotransferase (AST)와 지방질 역시 안전한 것으로 평가되었다[2].

백운풀은 항암, 면역, 항염, 항산화, 간보호, 신경보호 등의 다양한 효과를 지닌 것으로 알려져, 중국과 한국에서는 민간 요법으로서 암 치료를 위해 사용되고 있을 뿐 아니라 $[4,13]$, 그 효과가 과학적으로 입증되어 다수의 논문 및 특허가 보고 되었다[7, 10].

한편, 최근 생활수준 향상 및 의료기술 발달에 따른 평균수 명 연장에 의해 심장질환, 암, 당뇨 등 만성 또는 난치성 질환 의 발병률이 증가하고 있다. 따라서 각종 질환에 대한 예방적 개념이 도입되어 전통약물은 치료보다는 발병 이전에서의 역 할이 증대되었고, 한방 의약시장의 규모 또한 커지고 있는 실 정이다[1]. 이러한 전통약물의 수요가 증가됨에 따라 이들의 정확한 효능 및 안전성에 대한 평가 역시 중요한 항목으로 요구되기 시작하였으며, 그 요구를 충족하기 위하여 약효성분 이나 특이성분을 지표로 하는 품질평가법이 개발되고 있는 추세이다. 중국은 이러한 추세에 발맞추어 의약산업 10 차 5 개 
년 계획(2001 2005)에 따라 전국적인 규모로 중국 한약재의 지표성분과 함량 등을 규격화하여 품질 표준을 정하였고 공정 서에 수재된 생약 551 품목 중 약 200 품목에 대하여 지표성분 의 정량분석을 위한 품질평가법을 수립하였다[9]. 반면 우리나 라는 공정서에 수재된 생약은 520 품목이지만 지표성분의 품 질평가법이 확립된 품목은 약 50 품목에 불과하다. 이에 따라 2005년부터 식품의약품안전청 주관으로 한약재과학화 사업 을 추진하여 한약재로부터 지표성분 분리, 활성 탐색 및 분석 법 개발을 통한 한약재 표준화 연구가 진행 중이지만 한약재 의 품목이 한정적이어서 대상 한약재 외의 여타 천연물 소재 에 대한 연구는 매우 부족한 실정이다[8].

따라서, 건강기능식품 및 천연물신약 소재로서 우수함이 입 증된 백운풀로부터 이 식물이 대표적으로 함유하고 있는 iridoid와 anthaquinine을 분리, 정제하고 그 구조를 동정하였으 며, 아울러 산업화를 위한 기초 자료를 제공하기 위하여 이들 에 대한 최적 동시분석조건을 개발하여 정량법 및 유효성을 검증하고자 하였다.

\section{재료 및 방법}

\section{재료 및 시약}

건조된 백운풀 $(H$. diffusa, $10.8 \mathrm{~kg})$ 은 부산광역시에 소재하 는 대도농산에서 재배한 것을 제공받아 사용하였으며, 표본은 본 연구실에 보관하였다(voucher specimen no. KNUNPCHD-1). Column chromatography용 resin은 Merck 사 (Germany)의 Kieselgel 60 (Art.7734와 Art.9385)을 사용하였 고, TLC plate 또한 Merck사의 precoated Kieselgel 60F254 (Art.5715)및 RP-18 (Art.1.15685) 등을 사용하였다. 분석용 HPLC column은 Merck 사의 Merck Chromolith RP-18e (4.6× $100 \mathrm{~mm}$ ), Agilent사 (CA, USA)의 Agilent EclipseXDB-C18 $(4.6 \times 250 \mathrm{~mm}, 5 \mu \mathrm{m})$ 을 사용하였다.

HPLC는 Waters Breeze HPLC system을 사용하였으며, MPLC는 Yamazen MPLC system (GR-200)을 이용하였다. ${ }^{1} \mathrm{H}$ - 및 ${ }^{13} \mathrm{C}$-NMR spectra는 Bruker Avance Digital 400 spectrometer (Karlsruhe, Germany)로 400 과 $100 \mathrm{MHz}$ 에서 각각 측정하였다. Chemical shift는 TMS를 표준물질로 하여 $\delta$ (ppm)로 나타내었다.

\section{추출 및 정제}

건조된 백운풀 지상부 $(10.8 \mathrm{~kg})$ 를 약 101 의 $95 \% \mathrm{EtOH}$ (ethanol)로 $80^{\circ} \mathrm{C}$ 에서 5 시간 동안 2 회 반복 환류추출 하였다. $\mathrm{EtOH}$ 추출액을 여과지로 여과 후 감압 농축하여 $1,326.3 \mathrm{~g}$ 의 백운풀 $\mathrm{EtOH}$ 추출물을 얻을 수 있었으며, $\mathrm{CH}_{2} \mathrm{Cl}_{2}$ (dichloromethane), EtOAc (ethyl acetate) 및 $n-\mathrm{BuOH}$ (butanol)를 이용 하여 순차적으로 분획하였다. $\mathrm{CH}_{2} \mathrm{Cl}_{2}$ 층은 포화 $\mathrm{NaCl}$ 용액으 로 back washing한 후, 무수 $\mathrm{Na}_{2} \mathrm{SO}_{4}$ 로 탈수하고 감압 농축하
여 $\mathrm{CH}_{2} \mathrm{Cl}_{2}$ 가용성 분획 $343.1 \mathrm{~g}$ 을 얻을 수 있었다. 또한 $\mathrm{E} \mathrm{EAc}$ 층과 $n \mathrm{BuOH}$ 층에 대해서도 탈수 및 감압 농축을 실시하여 $\mathrm{EtOAc}$ 및 $n \mathrm{BuOH}$ 가용성 분획 $84.96 \mathrm{~g}$ 과 $208.6 \mathrm{~g}$ 을 각각 얻었다.

$\mathrm{CH}_{2} \mathrm{Cl}_{2}$ 가용성 분획 $(343.1 \mathrm{~g})$ 중 $9.26 \mathrm{~g}$ 을 이용하여 silica gel 컬럼 크로마토그래피를 실시하였다. 그 결과, $\mathrm{Fr} . \mathrm{C} 1 \sim \mathrm{C} 5$ 의 5 개의 분획을 얻을 수 있었으며, Fr. C3 (1.21g)를 silica gel 컬럼 크로마토그래피 $\left(3 \times 45 \mathrm{~cm}, n\right.$ Hexane- $-\mathrm{CH}_{2} \mathrm{Cl}_{2}=5: 1$ to $\left.1: 1\right)$ 하여 Fr. C3-1 C3-4의 4개 분획으로 나누었다. 이 중 Fr. C3-2 로부터 주황색 단일화합물 $\mathrm{HD} 14.3 \mathrm{mg}$ 을 얻었다.

또한 Fr. C3-4 (1.04 g)에 대한 silica gel 컬럼 크로마토그래 피 $\left(3 \times 57 \mathrm{~cm}, n\right.$-hexane- $\mathrm{CHCl}_{3}=1: 1$ to $100 \% \mathrm{CHCl}_{3} \rightarrow \mathrm{CHCl}_{3}$ $\mathrm{MeOH}($ methanol) $=100: 1$ to $50: 1 \rightarrow 100 \% \mathrm{MeOH}$ 를 실시하여 4개의 분획으로 나누고, 그 중 Fr. C3-4-2로부터 주황색 분말 $\mathrm{HD} 260.0 \mathrm{mg}$ 을 얻었다.

한편, $\mathrm{EtOAc}$ 가용성 분획(84.96 g)을 대상으로 silica gel 컬 럼 크로마토그래피 $\left(11 \times 53 \mathrm{~cm}, n\right.$-hexane- $\mathrm{CHCl}_{3}=1: 1$ to $100 \%$ $\mathrm{CHCl}_{3} \rightarrow \mathrm{CHCl}_{3}: \mathrm{MeOH}=100: 1$ to $3: 1 \rightarrow 100 \% \mathrm{MeOH}$ )를 실시 한 결과, $\mathrm{Fr}$. E1 E6의 6개 분획을 얻었으며 이들 중 Fr. E5를 다시 silica gel 크로마토그래피 $\left(8 \times 42 \mathrm{~cm}, \mathrm{CHCl}_{3}-\mathrm{MeOH}=10: 1\right.$ to 7:1)하여 $2.4 \mathrm{~g}$ 의 $\mathrm{HD} 3$ 를 분리할 수 있었다.

$\mathrm{HD} 4$ 는 Fr. E4 $(7.24 \mathrm{~g})$ 를 silica gel 컬럼 크로마토그래피 $\left(9 \times 38 \mathrm{~cm}, \mathrm{CHCl}_{3}-\mathrm{MeOH}=8: 1\right.$ to $5: 1 \rightarrow 100 \% \mathrm{MeOH}$ )하여 Fr. E4-1 E4-4의 4개 분획으로 나누고, 이 중 Fr. E4-2를 MPLC (Yamazen ODS-S-50B, $2630 \mathrm{~mm}$, 30 100\% MeOH, $5 \mathrm{ml} / \mathrm{min}$ ) 로 재정재하여 얻었다 $(884.9 \mathrm{mg})$.

\section{NMR 분석}

HD1 (digitolutein). ${ }^{1} \mathrm{H}-\mathrm{NMR}(400 \mathrm{MHz}$, chloroform- $d$ ) $\delta$ : 8.24 8.26 (2H, m, H-5 and H-8), 7.99 (1H, s, H-4), 7.75 7.77 $(2 \mathrm{H}, \mathrm{m}, \mathrm{H}-6$ and $\mathrm{H}-7), 6.75(1 \mathrm{H}, \mathrm{s}, \mathrm{OH}), 4.03\left(3 \mathrm{H}, \mathrm{s}, \mathrm{OCH}_{3}\right)$, $2.41\left(3 \mathrm{H}, \mathrm{s}, \mathrm{CH}_{3}\right) \cdot{ }^{13} \mathrm{C}-\mathrm{NMR}(100 \mathrm{MHz}$, chloroform-d) $\delta$ : 182.55 (C-9), 182.44 (C-10), 153.76 (C-3), 146.02 (C-4), 134.49 (C-10a), 133.77 (C-6), 133.67 (C-7), 132.98 (C-8a), 131.33 (C-2), 126.98 (C-5), 126.78 (C-8), 126.68 (C-1), 126.50 (C-9a), 123.52 (C-4a), $62.16\left(\mathrm{OCH}_{3}\right), 16.34\left(\mathrm{CH}_{3}\right)$.

HD2 (2-hydroxy-3-methylanthraquinone). ${ }^{1} \mathrm{H}-\mathrm{NMR}$ (400 MHz, DMSO-d) $\delta: 11.08$ (1H, s, OH), 8.14 8.18 (2H, m, H-5 and $\mathrm{H}-8), 7.97(1 \mathrm{H}, \mathrm{s}, \mathrm{H}-4), 7.86 \sim 7.92(2 \mathrm{H}, \mathrm{m}, \mathrm{H}-6$ and $\mathrm{H}-7)$, $7.55(1 \mathrm{H}, \mathrm{s}, \mathrm{H}-1), 2.29\left(3 \mathrm{H}, \mathrm{s}, \mathrm{CH}_{3}\right) .{ }^{13} \mathrm{C}-\mathrm{NMR}(100 \mathrm{MHz}$, DMSO-d) 8: 182.95 (C-10), 181.77 (C-9), 161.74 (C-3), 134.79 (C-7), 134.34 (C-6), 133.55 (C-8a), 133.53 (C-10a), 133.43 (C-4a), 132.34 (C-2), 126.92 (C-5), 126.89 (C-8), 125.36 (C-9a), 111.58 (C-4), $16.57\left(\mathrm{CH}_{3}\right)$.

HD3 [(E)-6-Opcoumaroyl scandoside methyl ester, as a major form]. ${ }^{1} \mathrm{H}-\mathrm{NMR}\left(400 \mathrm{MHz}\right.$, methanol- $\left.d_{4}\right) \delta: 7.51(1 \mathrm{H}$, s, H-3), $7.62\left(1 \mathrm{H}, \mathrm{d}, J=16.0 \mathrm{~Hz}, \mathrm{H}-7^{\prime}\right), 7.46(2 \mathrm{H}, \mathrm{d}, J=8.4 \mathrm{~Hz}$, 
H-2' and H-6'), $6.80\left(2 \mathrm{H}, \mathrm{d}, J=8.4 \mathrm{~Hz}, \mathrm{H}-3^{\prime}\right.$ and $\left.\mathrm{H}-5^{\prime}\right), 6.33$ $\left(1 \mathrm{H}, \mathrm{d},=16.0 \mathrm{~Hz}, \mathrm{H}-8^{\prime}\right), 5.85$ (1H, m, H-7), 5.67 (1H, m, H-6), $5.30(1 \mathrm{H}, \mathrm{d}, J=6.0 \mathrm{~Hz}, \mathrm{H}-1), 4.69(1 \mathrm{H}, \mathrm{d}, J=8.0 \mathrm{~Hz}, \mathrm{Glc}-1)$, $4.39(1 \mathrm{H}, \mathrm{d}, J=16.0 \mathrm{~Hz}, \mathrm{H}-10), 4.22(1 \mathrm{H}, \mathrm{d}, J=16.0 \mathrm{~Hz}, \mathrm{H}-10)$, $3.88(1 \mathrm{H}, \mathrm{d}, J=12.0 \mathrm{~Hz}, \mathrm{Glc}-6), 3.65$ (3H, s, H-12), 3.20-3.42 (4H, m, Glc-2, Glc-3, Glc-4, and Glc-5), $3.20(1 \mathrm{H}, \mathrm{d}$, J=9.0 Hz, H-5), 3.11 (1H, m, H-9). ${ }^{13} \mathrm{C}-\mathrm{NMR}(100 \mathrm{MHz} \text {, methanol- } \text { f })^{-}$

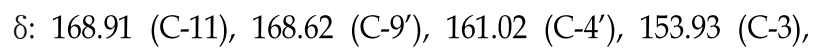
150.15 (C-8), 146.43 (C-7'), 131.04 (C-2' and C-6'), 127.19 (C-7, exchangeable), 127.15 (C-1', exchangeable), 116.72 (C-3' and C-5'), 115.33 (C-8'), 109.83 (C-4), 100.22 (Glc-1), 97.85 (C-1), 83.55 (C-6), 78.31 (Glc-3), 77.83 (Glc-5), 74.74 (Glc-2), 71.44 (Glc-4), 62.66 (Glc-6), 60.92 (C-10), 52.11 (C-12), 46.96 (C-9), 42.33 (C-5).

HD4 [(E)-6-O-methoxycinnamoyl scandoside methyl ester, as a major form]. ${ }^{1} \mathrm{H}-\mathrm{NMR}\left(400 \mathrm{MHz}\right.$, methanol- $\left.d_{4}\right) \delta$ : $7.66\left(1 \mathrm{H}, \mathrm{d}, J=15.2 \mathrm{~Hz}, \mathrm{H}-7^{\prime}\right), 7.56\left(2 \mathrm{H}, \mathrm{d}, J=8.0 \mathrm{~Hz}, \mathrm{H}-2^{\prime}\right.$ and H-6'), $7.52\left(1 \mathrm{H}\right.$, br s, H-3), $6.96\left(1 \mathrm{H}, \mathrm{d}, J=8.1 \mathrm{~Hz}, \mathrm{H}-3^{\prime}\right.$ and H-5') $6.39\left(1 \mathrm{H}, \mathrm{d}, J=15.2 \mathrm{~Hz}, \mathrm{H}-8^{\prime}\right), 5.85(1 \mathrm{H}, \mathrm{t}, J=1.2 \mathrm{~Hz}$, H-7), 5.69 (1H, m, H-6), $5.32(1 \mathrm{H}, \mathrm{d},=6.3 \mathrm{~Hz}, \mathrm{H}-1), 4.70(1 \mathrm{H}$, d, $\left.=8.1 \mathrm{~Hz}, \mathrm{H}-10^{\prime}\right), 4.39(1 \mathrm{H}, \mathrm{d},=16.2 \mathrm{~Hz}, \mathrm{H}-10), 4.22(1 \mathrm{H}$, d, $J=16.2 \mathrm{~Hz}, \mathrm{H}-10), 3.89(1 \mathrm{H}, \mathrm{dd}, J=11.7$ and $1.8 \mathrm{~Hz}, \mathrm{Glc}-6)$, $3.83(3 \mathrm{H}, \mathrm{s},-\mathrm{OMe}), 3.65$ (4H, m, H-12, Glc-6), 3.39 (1H, t, $J=9.0 \mathrm{~Hz}, \mathrm{H}-5), 3.36(1 \mathrm{H}, \mathrm{dd}, J=7.2$ and $5.4 \mathrm{~Hz}, \mathrm{Glc}-5), 3.32 \sim$ $3.27(2 \mathrm{H}, \mathrm{m}, \mathrm{Glc}-3$ and Glc-4), $3.22(1 \mathrm{H}, \mathrm{dd}, J=9.0$ and 8.2 Hz, Glc-2), 3.09 (1H, t, =7.2 Hz, H-9). ${ }^{13} \mathrm{C}$ NMR $(100 \mathrm{MHz}$, methanol-d d) $\delta: 169.20$ (C-11), 168.76 (C-9'), 163.23 (C-4'), 154.34 (C-3), 150.44 (C-8), 146.37 (C-7'), 131.25 (C-2' and C-6'), 128.44 (C-10), 127.45 (C-7), 116.57 (C-8'), 115.65 (C-3' and C-5'), 110.07 (C-4), 100.50 (Glc-1), 98.35 (C-1), 83.85 (C-6), 78.44 (Glc-3), 77.94 (Glc-5), 74.90 (Glc-2), 71.57 (Glc-4), 62.78 (Glc-6), 61.21 (C-10), 56.17 (C4'-OMe), 52.38 (C-12), 46.97 (C-9), 42.51 (C-5).

\section{$\mathrm{HPLC}$ 분석}

고정상으로는 Merck사의 Chromolieth RP-19e (4.6×100 $\mathrm{mm}, 5 \mu \mathrm{m}$ )를 사용하였으며, 실온에서 유속은 $2.0 \mathrm{ml} / \mathrm{min}$, $10 \mu \mathrm{l}$ 를 injection volume으로 설정하였다. 이동상으로는 $0.5 \%$ acetic acid가 포함된 $\mathrm{H}_{2} \mathrm{O}(\mathrm{A})$ 와 $\mathrm{MeOH}(\mathrm{B})$ 을 사용하여 최초 $80(\mathrm{~A}): 20(\mathrm{~B})(\mathrm{v} / \mathrm{v})$ 로 시작하여 9분 후 $40(\mathrm{~A}): 60(\mathrm{~B})$ 으로 gradient를 준 후, 18 분까지 유지시고, 20분에 다시 80 (A):20 (B)가 되도록 조건을 설정하였다. 분리된 화합물을 동시에 검출할 수 있는 적정파장으로 $280 \mathrm{~nm}$ 를 선택하였다.

\section{분리된 화합물의 순도 측정}

분리된 표준품의 순도 측정을 위한 HPLC 조건은 다음과
같다. 즉, 고정상으로는 Agilent Eclipse XDB-C18 (4.6×250 $\mathrm{mm}, 5 \mu \mathrm{m}$ ), 검출은 UV $280 \mathrm{~nm}$, 유속은 $0.9 \mathrm{ml} / \mathrm{min}$, 컬럼 온도는 $25^{\circ} \mathrm{C}$, 이동상으로는 $0.5 \%$ acetic acid가 포함된 $\mathrm{H}_{2} \mathrm{O}$ (A)와 $\mathrm{MeOH}(\mathrm{B})$ 을 사용하여 최초 (A) $95 \%$ 로 시작하여 50 분 후 $50 \%$ 가 되도록 gradient를 준 후, 5 분간 유지키는 조건을 설정하였다.

\section{검량선 작성 및 validation}

설정된 HPLC 조건을 이용하여 검량선 작성 및 지표성분의 validation을 실시하였다. 각각의 지표성분을 $\mathrm{MeOH}$ 에 용해 하여 $1 \mathrm{mg} / \mathrm{ml}$ 로 조제하고 이를 stock solution으로 하였다. 이 용액을 단계적으로 희석하여 농도가 $0.1,0.25,0.5,1.0,2.5$, $5.0 \mu \mathrm{g} / \mathrm{ml}$ 로 총 6개의 구간을 설정하였으며 $0.45 \mu \mathrm{m} \mathrm{mem-}$ brane filter로 여과하여 여액을 HPLC에 주입하고, 검출된 peak area와 농도와의 상관관계를 이용하여 검량선을 작성하 였다. 분석기기의 LOD (limit of detection)는 signal대 noise의 비를 3으로 설정하였으며, LOQ (limit of quantification)는 $\mathrm{LOD} \times 3.3$ 일 때의 농도로 구하였다. 또한 일내 정밀성과 반복 성을 검토하기 위하여 하루 3 반복 측정하였으며, 일간 정밀성 과 반복성은 3 일 동안 반복 측정하여 값을 도출하였다.

\section{결과 및 고찰}

\section{지표성분의 분리 및 구조동정}

백운풀의 지표성분 설정을 위하여 백운풀을 $\mathrm{EtOH}$ 로 추출 한 다음, 추출물에 대해 각종 크로마토그래피를 실시한 결과, $\mathrm{HD} 1 \mathrm{HD} 4$ 의 네 가지 화합물을 얻을 수 있었다. 화합물 HD1 은 주황색 분말로 얻어졌으며, ${ }^{1} \mathrm{H}-\mathrm{NMR}$ 분석 결과, $\delta 4.03$ 에서 methoxyl group에 의한 singlet이 관측되었으며, $\delta$ 2.41에서 methyl singlet이 검출되었다. 또한 $\delta 6.75$ 에서 hydroxyl proton resonance를 관찰할 수 있었다. ${ }^{13} \mathrm{C}-\mathrm{NMR}$ 에서 $\delta 182.55$ 와 $\delta$ 182.44에서 ketone 유래의 signal이 관측되었으며, $\delta$ 62.16와 $\delta$ 16.34에서 나타난 peak는 각각 methoxyl group과 methyl group 유래인 것으로 판단되었다. 이상의 결과를 볼 때, 이 화합물은 anthraquinone의 일종일 것으로 예측되었으며 NMR data를 문헌치와 비교하여 digitolutein (2-hydroxy-1methoxy-3-methylanthraquinone)으로 구조 동정할 수 있었 다[18]. 이 화합물은 앞서 기술한 조건에서 $\mathrm{HPLC}$ 로 분석하였 을 때 $95.2 \%$ 의 순도를 나타내었다.

$\mathrm{HD} 2$ 는 주황색 분말로 얻어졌으며 육안적 성상 및 TLC 에 서의 거동이 HD1과 매우 유사하였을 뿐 아니라, NMR spectrum 역시 매우 비슷한 양상을 나타내었다. 즉, ${ }^{1} \mathrm{H}-\mathrm{NMR}$ 측정 결과 $\delta$ 2.29에서 methyl group에 의한 single이 관측되었으며 $\delta 11.08$ 에서는 수소결합한 hydroxyl proton resonance가 관측 되었다. ${ }^{13} \mathrm{C}-\mathrm{NMR}$ 분석 결과, 2 개의 ketone $(\delta 182.95,181.77)$ 및 한 개의 methyl proton ( $\delta 16.57)$ 이 관측되어 HD1과 같은 
anthraquinone의 일종으로 판단되었다. 한편, $\mathrm{HD} 1$ 과는 달리 $\mathrm{HD} 2$ 에서는 methoxyl proton이 발견되지 않아 HD2는 2-hydroxy-3-methylanthraquinone으로 예측되었으며 이 구조는 $\mathrm{NMR}$ 분석치를 문헌치와 대조하여 확정하였다[16]. 분리된 $\mathrm{HD} 2$ 는 앞서 기술한 HPLC 분석 조건으로 분석 시 $93.5 \%$ 의 순도를 나타내는 것으로 확인되었다.

$\mathrm{HD} 3$ 는 $10 \%$ 황산을 이용한 정성반응에서 진한 청색으로 발색되었다. 순도확인을 위한 HPLC 분석에서 2개의 peak가 관측되었으며, 그 면적 비율은 약 4:1이었다. ${ }^{1} \mathrm{H}-\mathrm{NMR}$ spectrum에서 major peak로 나타나는 $\delta 7.62 / 6.33(J=16.0 \mathrm{~Hz})$ 과 minor signal로 나타나는 $\delta 6.86 / 5.78(J=12.0 \mathrm{~Hz})$ 이 혼재해 있는 양상으로 미루어, HD3는 C-7'과 C-8'이 trans 및 cis의 두 가지 configuration으로 존재하는 혼합물일 것으로 예상되 었다. 그 이외에 iridoid 계열 화합물에 특징적인 $\delta 7.51(\mathrm{H}-3)$, $5.85(\mathrm{H}-7)$ 등의 signal 들이 관측되었으며, $\delta 7.46(2 \mathrm{H})$ 및 6.80 (2H)에서 나타나는 전형적인 1,4-disubstituted benzene ring 의 signal, $\delta 3.65$ 의 methoxyl proton들로 미루어 이 화합물은 (E)- 및 (Z)-6-O-pcoumaroyl scandoside methyl ester가 약 4:1 로 혼합된 화합물인 것으로 판단되었으며 문헌치와의 비교에 의해 확인하였다[3]. 일반적으로 $(E)$ - 및 (Z)-configuration은 열 및 빛 등의 에너지가 가해지면 쉽게 상호 전환될 수 있는 것으로 알려져 있으며, 실제로 분리된 $\mathrm{HD} 3$ 를 약 24 시간 동안 UV254 nm에 방치할 경우 약 $10.8 \%$ 증가하였다(데이터 미제 시). 따라서 $\mathrm{HD} 3$ 는 단일 이성질체를 분리하는 과정 중에서, 또는 분리하였다 하더라도 분석 과정 중에서 상호전환이 일어 나게 되므로, 혼합물의 상태로 정량하도록 하였다. 두 이성질 체의 합으로서 $\mathrm{HD} 3$ 의 순도는 $99 \%$ 이상이었다.

$\mathrm{HD} 4$ 역시 $\mathrm{HD} 3$ 과 같이 $10 \%$ 황산에 진한 청색으로 발색되 었으며, 순도확인을 위한 HPLC 분석에서 HD3과 동일하게 2개의 peak가 4:1로 나타났다. 다만, ${ }^{1} \mathrm{H}-\mathrm{NMR}$ 분석 결과, $\mathrm{HD} 4$ 에서는 HD3에 비해 한 개 많은 methoxyl group이 $\delta 3.83(3 \mathrm{H}$, s)에서 발견되어 HD3 구조 중 pcoumaroyl moiety의 hydroxyl group이 methoxyl group으로 치환된 (E)-6-O-methox- ycinnamoyl scandoside methyl ester일 것으로 예상하였다. 이 구조는 기존의 문헌치와 NMR data를 비교하여 확정하였 다[14]. 두 이성 질체의 합으로서 HD4의 순도는 사용한 HPLC 조건에서 $99 \%$ 이상이었다. 분리한 표준품의 구조는 Fig. 1 에 제시하였다.

\section{검량선 작성 및 validation}

한편, HD1 4 이외에도 ursolic acid, daphylloside, geniposide 등의 화합물이 본 실험을 통해 분리되었으나 식물에 널리 분포되어 있는 성분이거나 또는 미량 존재하는 성분으로서 지표성분은 첫째, 성분을 대표할 수 있을 정도로 함유량이 높 을 것, 둘째, 분리하기 쉬울 것, 셋째, 가능한 그 식물에 특이적 인 화합물일 것, 넷째, 분석방법이 간단할 것 등, 지표성분으로 서의 조건을 충족하기 어려워 지표성분으로서 HD1 4을 설정 하게 되었다.

$\mathrm{HD} 1 \sim 4$ 의 검량선을 작성한 결과 상관계수 $\left(\mathrm{R}^{2}\right)$ 는 각각 $0.9991,0.9999,0.9993,0.9998$ 로 높은 직선성을 보였으며, LOD (limit of detection)는 각각 $0.05,0.06,0.03,0.07 \mu \mathrm{g} / \mathrm{ml}$ 로, LOQ (limit of quantification)는 $0.165,0.198,0.99,0.231 \mathrm{\mu g} / \mathrm{ml}$ 수준 이었다(Table 1). 또한 면적 비에 대한 재현성 RSD (Relative Standard Deviation, \%)는 각각 $0.16,0.90,1.18,0.58 \%$ 의 값을 보였으며(Table 2) 일내 CV (Coefficient of Validation, \%)는 각각 $0.23,2.00,1.18,0.26 \%$ 를, 일내 정확도는 $102.80,96.08$, $108.44,94.60 \%$ 로 나타났다(Table 3$)$. 한편, 일간 $\mathrm{CV}(\%)$ 는 각 각 $0.25,1.16,0.98,0.30 \%$ 를, 일간 정확도는 $102.82,98.58$, $110.23,94.73 \%$ 이었다(Table 4 ).

\section{최적 $\mathrm{HPLC}$ 분석 조건 확립}

백운풀 추출물의 지표성분으로 설정한 화합물의 정량을 위 해 최적 HPLC 조건을 검토한 결과, column은 Merck Chromolith RP-18e $(100 \times 4.6 \mathrm{~mm}, 5 \mu \mathrm{m})$, 실온, 유속 $2.0 \mathrm{ml} / \mathrm{min}$, injection volume $10 \mu \mathrm{l}$, 이동상으로는 $0.5 \%$ acetic acid가 포함 된 $\mathrm{H}_{2} \mathrm{O}(\mathrm{A})$ 와 methanol $(\mathrm{B})$ 을 사용하여 최초 $80 \%(\mathrm{~A})$ 로 시작<smiles>[R]c1c(O)c(C)cc2c1C(=O)c1ccccc1C2=O</smiles>

$\mathrm{HD1}: \mathrm{R}=\mathrm{OCH}_{3}$ $H D 2: R=H$

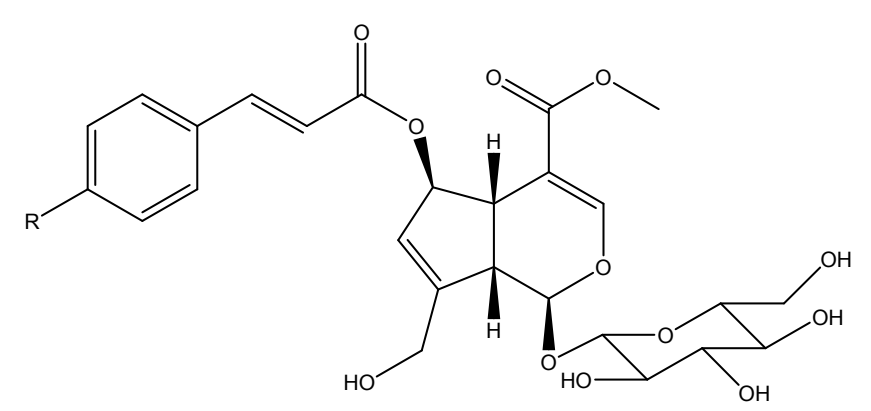

HD3: $\mathrm{R}=\mathrm{OH}$ HD4: $\mathrm{R}=\mathrm{OCH}_{3}$

Fig. 1. The structures of marker compounds 1-4 isolated from $H$. diffusa. HD1: digitolutein, HD2: 2-hydroxy-3-methylanthraquinone, HD3: (E/L)-6-O-p-coumaroyl scandoside methyl ester, HD4: (E/L)-6-O-p-methoxycinnamoyl scandoside methylester. 
Table 1. Range, linearity, LOD, and LOQ

\begin{tabular}{ccccccc}
\hline Compound & $\begin{array}{c}\text { Linear range } \\
(\mu \mathrm{g})\end{array}$ & Slope & Intercept & $\begin{array}{c}\text { Correlation } \\
\text { coefficient }\end{array}$ & $\begin{array}{c}\text { LOD } \\
(\mu \mathrm{g} / \mathrm{ml})\end{array}$ & $\begin{array}{c}\text { LOQ } \\
(\mu \mathrm{g} / \mathrm{ml})\end{array}$ \\
\hline HD1 & $0.1-0.5$ & 1407361 & 41508 & 0.9991 & 0.05 & 0.165 \\
HD2 & $0.1-0.5$ & 1482718 & -27516 & 0.9999 & 0.06 & 0.198 \\
HD3 & $0.1-0.5$ & 559421 & -43370 & 0.9993 & 0.03 & 0.099 \\
HD4 & $0.1-0.5$ & 516425 & 19517 & 0.9998 & 0.07 & 0.231 \\
\hline
\end{tabular}

Table 2. Reproducibility of peak area

\begin{tabular}{ccccc}
\hline \multirow{2}{*}{ Compound } & \multirow{2}{*}{ Spiked Conc. $(\mu \mathrm{g})$} & \multicolumn{3}{c}{ Peak area } \\
\cline { 3 - 5 } & & Average & SD & RSD $(\%)$ \\
\hline HD1 & 0.25 & 0.2597 & 0.0004 & 0.16 \\
HD2 & 0.25 & 0.2506 & 0.0002 & 0.90 \\
HD3 & 0.25 & 0.2711 & 0.0032 & 1.18 \\
HD4 & 0.25 & 0.2378 & 0.0014 & 0.58 \\
\hline
\end{tabular}

Table 3. Intra-day accuracy and precision

\begin{tabular}{cccccc}
\hline \multirow{2}{*}{ Compound } & \multirow{2}{*}{ Spiked Conc. $(\mu \mathrm{g})$} & \multicolumn{5}{c}{ Peak area } \\
\cline { 3 - 6 } & & Observed Conc. $(\mu \mathrm{g})$ & $\mathrm{SD}$ & $\mathrm{CV}(\%)$ & Accuracy $(\%)$ \\
\hline HD1 & 0.25 & 0.2597 & 0.0004 & 0.16 & 102.80 \\
HD2 & 0.25 & 0.2506 & 0.0002 & 0.90 & 90.08 \\
HD3 & 0.25 & 0.2711 & 0.0032 & 1.18 & 108.44 \\
HD4 & 0.25 & 0.2378 & 0.0014 & 0.58 & 94.60 \\
\hline
\end{tabular}

Table 4. Inter-day accuracy and precision

\begin{tabular}{ccccrcr}
\hline \multirow{2}{*}{ Compound } & \multirow{2}{*}{ Spiked Conc. $(\mu \mathrm{g})$} & \multicolumn{5}{c}{ Peak area } \\
\cline { 3 - 6 } & & Observed Conc. $(\mu \mathrm{g})$ & \multicolumn{1}{c}{ SD } & \multicolumn{1}{c}{ Bias } & CV $(\%)$ & Accuracy $(\%)$ \\
\hline HD1 & 0.25 & 0.2571 & 0.0007 & -0.0071 & 0.25 & 102.82 \\
HD2 & 0.25 & 0.2464 & 0.0029 & 0.0036 & 1.16 & 98.58 \\
HD3 & 0.25 & 0.2756 & 0.0027 & -0.0256 & 0.98 & 110.23 \\
HD4 & 0.25 & 0.2368 & 0.0007 & 0.0132 & 0.30 & 94.73 \\
\hline
\end{tabular}

하여 9 분 후 $40 \%(\mathrm{~A})$ 가 되도록 gradient를 준 다음 18 분까지 유지하는 조건을 설정하였다. PDA (photodiode array detector)를 이용하여 전체의 파장을 분석한 후, 적정파장을 280 $\mathrm{nm}$ 로 설정하였으며, 이 방법으로 백운풀 ethanol 추출물을 분석할 경우 다른 성분의 방해 없이 20 분 이내에 모든 지표성 분을 분석할 수 있었다(Fig. 2).

백운풀 중 함유되어 있는 성분의 정량법과 관련한 논문으로 는 비색정량법에 의해 total flavonoid를 정량하거나[15], pcoumaric acid, oleanolic acid 등과 같이 백운풀에 특징적이 라기 보다는 대부분의 식물에 공통적으로 들어 있는 일반 성 분을 대상으로 하는 정량법 개발이 대부분이며[12, 17], 백운풀 에 특이적으로 다량, 다수 함유되어 있는 것으로 알려져 있는 iridoid와 anthraquine에 대한 보고는 드물다. Iridoid 계통의 화합물인 scandoside 유도체 단일 성분에 대한 정량법이 보고
되었으며[3, 6], 2 종의 anthraquinone을 동시분석한 것 등이 보고되어 있다[5]. 한편, 다성분의 동시분석법으로는 caffeic acid, quercetin, campherenol의 3 종 화합물을 HPLC로 정량 한 보문이 보고되었을 뿐이며[11] 백운풀의 특성을 잘 나타낼 수 있는 irdoid와 anthraquine에 대한 동시분석법 개발은 이루 어지고 있지 않다.

본 연구에서 확립한 방법은 기존에 백운풀 중의 anthraquinone만을 동시 분석하는 방법[5] 및 2 종의 iridoid를 분석하는 기존의 방법[3]에 비하여 서로 다른 두 가지 골격을 갖는 4 종의 화합물을 동시에 분석함에도 불구하고 분석에 소요되는 시간이 20 분 이상 단축되어 매우 효율성이 높다고 판단된다. 본 연구결과는 백운풀을 소재로 하는 건강기능식품이나 천연 물신약 개발 및 제품화, 그리고 이들의 산업화 시 품질관리에 이용될 수 있을 것으로 기대된다. 


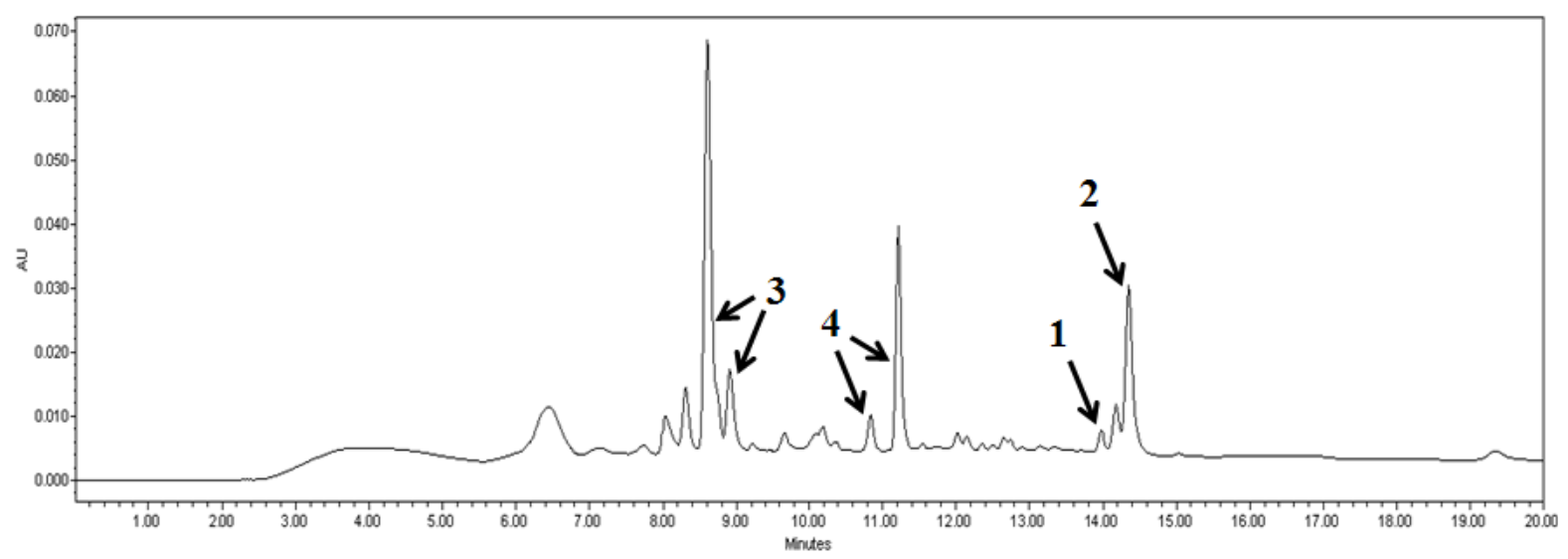

Fig. 2. Typical HPLC profile of $H$ diffusa Column: Merck Chromolith RP-18e $(100 \times 4.6 \mathrm{~mm}, 5 \mu \mathrm{m})$, Temperature: room temperature, Flow rate: $2.0 \mathrm{ml} / \mathrm{min}$, Injection volume: $10 \mu \mathrm{l}$ Mobile phase: $\mathrm{A}) \mathrm{H}_{2} \mathrm{O}+0.5 \%$ acetic acid, B) methanol $+0.5 \%$ acetic acid, Detection: $280 \mathrm{~nm}$, Run time: $20 \mathrm{~min}$.

\section{감사의 글}

본 연구는 농림수산식품부가 지원하고, 농림기술기획평가 원이 관리하는 고부가가치 식품기술개발사업(No. 1100-16-3) 의 지원에 의해 수행되었음을 감사하게 생각합니다.

\section{References}

1. Byun, M. S., Seo, B. N. and Kim, K. W. 2008. Analysis of flower teas for their oriental medicinal efficacy through literature. Flower Res J 26, 449-453.

2. Kim, S. C., Lee, S. S. and Li, J. I. 2001. Pharmacologic evaluation of some anti-cancer plants in China and its clinical use of traditional Chinese medicine. Plant Res 14, 85-91.

3. Liang, Z. T., Jiang, Z. H., Leung K. S. Y. and Zhao, Z. Z. 2006. Determination of iridoid glucosides for quality assessment of Herba Oldenalandiae by high-performance liquid chromatography. Chem Pharm Bull 54, 1131-1137.

4. Lin, J., Wei, L., Xu, W., Hong, Z., Liu, X. and Peng, J. 2011. Effect of Hedyotis Diffusa Willd extract on tumor angiogenesis. Mol Med Rep 4, 1283-1288.

5. Li, J., Yu, L., Ma, L., Li, Y. and Guo, X. 2008. Simultaneous HPLC determination of two anthraquinones in Hedyotis diffusa Willd. of different sources. Yaowu Fenxi Zazhi 28, 1478-1480.

6. Liu, K., Guo, Y., Zhu, D., Ma, L. and Guo, X. 2006. HPLC quantitative analysis of $E-6-O$-pcoumaroyl scandoside methyl ester in Hedyotis diffusa Willd. Yaowu Fenxi Zazhi 26, 1385-1387.

7. Liu, X. 2013. A chinese medicinal composition for treating liver cancer. Faming Zhuanli Shenqing CN 103191267 A 20130710.

8. Oh, M. H., Jo, U., Jang, S. Y., Park, J. Y., Lee, J. P., Sung, L. S., Gang, I. H., Kim, J. H., Kim, J. H., Kim, H. U., Yuk, C. S. and Park, J. H. 2004. Project for Establishment and Renewal of Herbal Drug Regulations (III). Korea Food and Drug Administration 8, 165-175.
9. Park, H. J. 2009. Simultaneus HPLC quantification of $(E)$ harpagoside, p-methoxycinnamic acid, and pmethoxycinnamic acid methyl ester in Scrophulariae Radix. Kyungpook Natl Univ MS thesis, 1-2.

10. Quan, X. Q. 2011. Action of Hedyotis diffusa and its effective components for the treatment of cancer. Zhongyi Xuebao 26, 1155-1157.

11. Shao, Z., Jia, X., Shi, F., Wang, J. and Chen, Y. 2009. Simultaneous determination of caffeic acid, quercetin and campherenol from Hedyotis diffusa Willd by HPLC. Zhongchengyao 31, 1894-1897.

12. Tang, X. L., Liu, J., Li, G. Q., Qiu, P. J. and Zhong, H. M. 2008. A rapid method for the quantitative determination of pcoumaric acid in Hedyotis diffusa from different sources. Zhongguo Xiandai Yingyong Yaoxue 25, 408-410.

13. Xu, B. J. and Sung, C. K. 2005. Chemical constituents and pharmacological activities of Hedyotis diffusa. Nat Prod Sci 11, 1-9.

14. Xu, G. H., Kim, Y. H., Chi, S. W., Choo, S. J., Ryoo, I. J., Ahn, J. S. and Yoo, I. D. 2010. Evaluation of human neutrophil elastase inhibitory effect of iridoid glycosides from Hedyotis diffusa. Bioorg Med Chem Lett 20, 513-515.

15. Yang, Y., Xu, J., Liu, Y. H. and Xiong, J. 2011. Study on quantitative determination of total flavonoids in Hedyotis diffusa Willd by colorimetry. Zhonghua Zhongyiyao Xuekan 29, 313-316.

16. Zhang, F. X, Brian W. and Hadfield, J. A. 1996. Preparation of naturally occurring anthraquinones. Synthetic Comm 26, 49-62.

17. Zhang, Y., Tan, X., Cui, X., Jiang, G. and Zhu, Y. 2010. Quantitative determination of ursolic acid and oleanolic acid in Baihuasheshecao (Herba Hedyotis diffusae) produced from different places by HPLC. Beijing Zhongyiyao Daxue Xuebao 33, 274-276.

18. Zhou, Y. J., Wu, K. S., Zeng, G. Y., Tan, J. B., Xu, K. P., Li, F. S. and Tan, G. S. 2007. Studies on constituents of Oldenlandia diffusa. Zhongguo Zhongyao ZaZhi 32, 590-593. 


\section{초록 : 백운풀의 지표성분 설정 및 품질표준화를 위한 정량 분석법}

방한열 $^{1} \cdot$ 양은주 ${ }^{2} \cdot$ 김정아 ${ }^{2} \cdot$ 송경식 ${ }^{2 *}$

(경북대학교 약학대학 ${ }^{1}$ 농화학과, ${ }^{2}$ 약학과)

백운풀의 품질표준화를 위하여 지표 성분을 설정하고자 하였다. 백운풀의 에탄올 추출물 중 비교적 백운풀에 특이하고, 다량 함유되어 있는 화합물을 분리한 다음 ${ }^{1} \mathrm{H}$ 및 ${ }^{13} \mathrm{C}-\mathrm{NMR}$ 을 이용하여 구조 동정한 결과, $\mathrm{HD} 1$ (digitolutein), HD2 (2-hydroxy-3-methylanthraquinone), HD3 [(E/C)-6-O-p-coumaroyl scandoside methyl ester, 4:1] 및 HD4 [(E/C)-6-O-p-methoxycinnamoyl scandoside methyl ester, 4:1]의 4 종 화합물을 표준품으로 확보할 수 있었다. HD1 4의 검량선을 작성한 결과 상관계수 $\left(R^{2}\right)$ 는 각각 $0.9991,0.9999,0.9993,0.9998$ 로 높은 직선성을 보였으며, LOD는 $0.05,0.06,0.03,0.07 \mu \mathrm{g} / \mathrm{ml}$ 로, LOQ는 $0.165,0.198,0.99,0.231 \mu \mathrm{g} / \mathrm{ml}$ 수준으로 나타났다. 또한 면적 비에 대한 재현성 $\mathrm{RSD}(\%)$ 는 각각 $0.16,0.90,1.18,0.58 \%$ 의 값을 보였으며 일내 CV (\%)는 $0.23,2.00,1.18$, $0.26 \%$ 를, 일내 정확도는 $102.80,96.08,108.44,94.60 \%$ 로 나타났다. 한편, 일간 $\mathrm{CV}(\%)$ 는 각각 $0.25,1.16,0.98$, $0.30 \%$, 일간 정확도는 $102.82,98.58,110.23,94.73 \%$ 였다. 백운풀 추출물 중 설정한 4 종 지표성분의 정량을 위한 최적 HPLC 조건을 검토한 결과, 고정상은 Merck Chromolith RP- $18 \mathrm{e}(100 \times 4.6 \mathrm{~mm}, 5 \mu \mathrm{m})$, 컬럼 온도는 실온, 검출은 UV $280 \mathrm{~nm}$, 유속 $2.0 \mathrm{ml} / \mathrm{min}$, injection volume $10 \mu \mathrm{l}$, 이동상으로는 $0.5 \%$ acetic acid가 포함된 $\mathrm{H}_{2} \mathrm{O}(\mathrm{A})$ 와 methanol $(\mathrm{B})$ 을 사용하여 최초 $80 \%(\mathrm{~A})$ 로 시작하여 9분 후 $40 \%(\mathrm{~A})$ 가 되도록 gradient를 준 다음 18 분까지 유지하는 조건을 설정하였다. 이 방법으로 백운풀 ethanol 추출물을 분석할 경우 다른 성분의 방해 없이 20 분 이내에 모든 지표성분을 분석할 수 있었다. 연구결과는 백운풀의 건강기능식품 및 천연물신약 개발 및 품질관리 에 도움을 줄 수 있을 것으로 기대된다. 